\title{
Intelligent Parking System
}

\author{
Abdul Ahad, Zishan Raza Khan, Syed Aqeel Ahmad \\ Department of Civil Engineering, Integral University, Lucknow, India \\ Email: abdulahad48471@gmail.com
}

Received 18 January 2016; accepted 26 April 2016; published 29 April 2016

Copyright (C) 2016 by author and Scientific Research Publishing Inc.

This work is licensed under the Creative Commons Attribution International License (CC BY). http://creativecommons.org/licenses/by/4.0/

(c) (i) Open Access

\section{Abstract}

The searching of parking burns a lot of barrels of the world's oil every day. Car parking problem is a major contributor in congestion of traffic and has been, still a major problem with increasing vehicle size in the luxurious segment and also confines parking spaces in urban cities. The rapid growth in the number of vehicles worldwide is intensifying the problem of the lack of parking space. As the global population continues to urbanize, without a well-planned, convenience-driven retreat from the car, these problems will worsen in many countries. The current unmanaged car parks and transportation facilities make it difficult to accommodate the increasing number of vehicles in a proper, convenient manner so it is necessary to have an efficient and smart parking system. Smart parking management systems are capable of providing extreme level of convenience to the drivers. In this paper, a proposed web App system, named "Park Easy" is based on the usage of smart phones, sensors monitoring techniques with a camera which is used as a sensor to take photos to show the occupancy of cars parks. By implementing this system, the utilization of parking spaces will increase. It allocates available parking space to a given driver to park their vehicle, renew the availability of the parking space when the car leaves and compute the charges due. Smart parking App, "Park Easy", will also enable most important techniques to provide all the possible shortage route for parking from any area of the city mainly, it helps to predict accurately and sense spot/vehicle occupancy in real-time.

\section{Keywords}

Smart Parking System, Android App, Sensing Camera, M2M Services Innovation, Parking Zones

\section{Introduction}

The searching of a parking space in a parking lot in commercial areas is a so much frustrating activity for many people. More problem increases with the high growth rate in the registration of new cars worldwide. There are many parking places of modern technologies existing but many drivers don't know about the parking blocks or 
about parking system. To overcome from these problems of congestion of traffic and save the fuels from it, the unique step of solution is smart parking.

According to a report, smart parking can result in 220,000 gallons of fuels saving till 2030 and approx. 300,000 gallons of fuels saved by 2050 [1], if implemented successfully, as shown in Figure 1.

The intelligent or smart parking system must be proposed for searching the vacant or about to vacant parking space [1]. The proposed system based on image processing technique which captures and processes the rounded image drawn at parking lot produces the information of the empty car parking spaces, with the help of the Android App, "Park Easy" App on the mobile phones by the existing data records or by searching the spaces through App. In smart parking system, users can access data to determine the availability of spots for parking and then pay for them with their mobile phones. Also the App provides all possible shortage routes for the parking from any area of the city. Thus, smart parking improves the utilization of existing parking, leading to greater revenue for parking owners. It also benefits for the environment and plays a major role in creating eco-friendly environment.

Smart parking programs are now being deployed in San Francisco, Los Angeles, Stockholm, Beijing, Shanghai, São Paulo and the Netherlands. In Los Angeles, low-power sensors and smart meters track the occupancy of parking spaces throughout the Hollywood district, one of its most congested areas. Los Angeles sees a return on its investment in smart parking within three months [2].

Few years back, individual parking systems efforts so far have been locally successful but uncoordinated, operating in their own entrepreneurial vacuums without taking advantage of universally-applicable insights to scale their operations citywide or globally. The gap between existing parking programs and more widespread transportation system planning is, at the global scale, a massive missed opportunity for cities to reduce transportation-related emissions. The concern of mobility in urban areas in recent decades has become an increasingly serious problem and difficult to manage: the quality of life, not only of drivers, is strongly influenced due to inefficiencies and diseconomies of urban congestion. This raises also serious problems of pollution and noise and wide spaces of the city are occupied by parked cars [3]. However, it is possible to overcome all of the issues of collaboration, from this technique using the sensors, real time data collection, data operators and smart phones [2]. Thus, from this purposed "Park Easy" App, the user can occupy data, tend to have many owners and is not standardized or accessible in a way that will allow software developers to turn it into user-friendly applications. With smart phones, capturing more and more of the global telecommunications market in both developing and developed nations, software entrepreneurs are able to collect and analyze data and deliver insights and information to consumers in brand new ways that do not require installation of new hardware.

\section{Need and Benefits Analysis of Smart Parking [1]}

- Optimize parking space usage.

- Help traffic in the city flow more freely.

- Guides residents and visitors to available parking.

- Accurately predict and sense spot/vehicle occupancy in real-time.

- Enables intelligent decisions using data, including real-time status applications and historical analytics reports.

- Smart parking plays a major role in creating better urban environment by reducing the emission of $\mathrm{CO}_{2}$ and other pollutants.

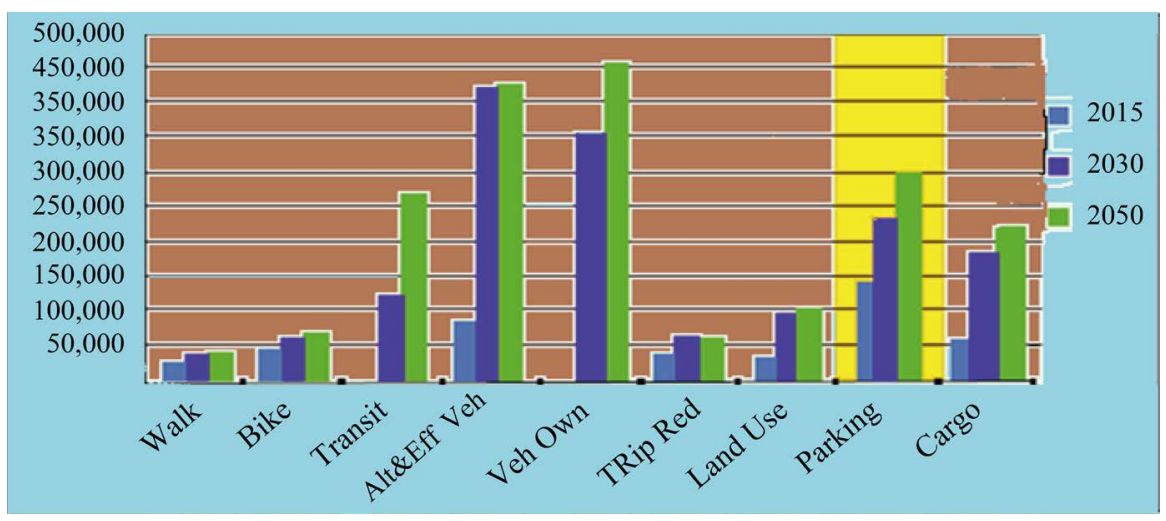

Figure 1. Assumption of saving fuel consumption. 


\section{Methodology}

Smart parking helps one of the biggest problems on driving in urban areas, finding empty parking spaces and controlling illegal parking [1]. When deployed as a system, smart parking thus reduces car emissions in urban centers by reducing the need for people to needlessly circle city blocks searching for parking. It also permits cities to carefully manage their parking supply. Smart parking systems typically obtain information about available parking spaces in a particular commercial area and process available positions for vehicles, it involves using sensors, real-time data collection, and mobile-phone-enabled automated payment systems that allow people to reserve parking in advance or very accurately predict where they will likely find a spot [1].

Generally, the use of smart phones is so common for the peoples with having the internet. So, this proposed app named, "Park Easy" as android web App that helped local residents as well as peoples of other cities travel or visitors for finding the parking spaces.

In the "Park Easy" App, users can enter the area's address of a spot where they wanted to reach or the parking place in a particular area, or places from which they reach his destination by walking, as shown in Figure 2, and the flow chart of the process is shown in Figure 3. It provide the easy parking spaces by using this technique that allow people to reserve parking in advance or very accurately predict where they will likely find a spot. When deployed as a system, smart parking reduces the emission of fuel wastage by reducing needlessly circles in city blocks for searching parking [1]. By using this app, other users nearby will see that spot vacancy on the mobile phones or laptops, with leaving time of the first user, if they search the area. The pictures with detail of entire procedure of the parking system are given below in Figures 5-8.

The app can expanded to cities nationwide and provides transit information about schedules, delays, accidents and also the condition of the traffic of the route, and provide the alternative routes of the parking. The typical flow chart of the using process of Smart parking system is shown in the Figure 4. This purposed technique of using android app present a system that will be detect the availability of car parks and shows the driver where the car parking spaces are available.

In this work, a camera is used with a sensor to take photos to show the occupancy of car parks. The camera can detect the presence of many cars at once. Also, the camera can be easily moved to detect different car parking lots. By having this image, the particular car parks vacant can be known and then the processed information was used to guide a driver to an available car park rather than wasting time to find the space [2]. The camera detect the vacant space of parking and shown on the screen with Green circles are placed on the vacant car parks. Green circle helps users so that users can easily differentiate whether a car is parked in a spot or not. If there is a car on the spot then the green circle will not be seen [4]. The proposed system has been developed in both software and hardware platform as shown the working process of this technique in Figure 4.

Whether you are at airports, railway stations, shopping centers, hotels, or in commercial doesn't matter created for the parking by using this android app. This technique will guide easily from app and provides shortage solution for the parking. It provides reliable information about the occupancy of all parking spaces [5].

Developing smart parking solutions within a city require standardized data and management; mobile phone integration; hardware and software innovation; and coordination among various stakeholders such as: parking facility owners, municipalities, transportation authorities, customers, and software developers. These technical solutions and stakeholders are the same data structures and development groups integral to making a smart phone-enabled, multimodal, fully integrated transportation solution a reality. In effect, the technical enablers and multi-stakeholder coordination effort behind development of a local smart parking solution creates a launch-pad toward full transportation system integration [1]. The smart parking can actually transform of our urban landscapes, making them more amenable to people rather than cars. With the advent of smart parking and more mobility alternatives to personal vehicles, better use of existing parking will drive decreased demand for the country's parking space surplus and for surface parking. Cities can further accelerate this system by updating building codes and land use policies to reflect reduced need for parking, a move which drives down building costs and encourages more varied development options. In the end, urban spaces can become greener, cleaner, more compact, and more inherently walk-able, bike-able and serviceable by a multimodal transportation system [2].

\subsection{Description of Smart Parking System}

The smart parking system includes many systems which perform simultaneously in one platform for unique task within a time. The description of the smart parking system is clearly given as [1]: 


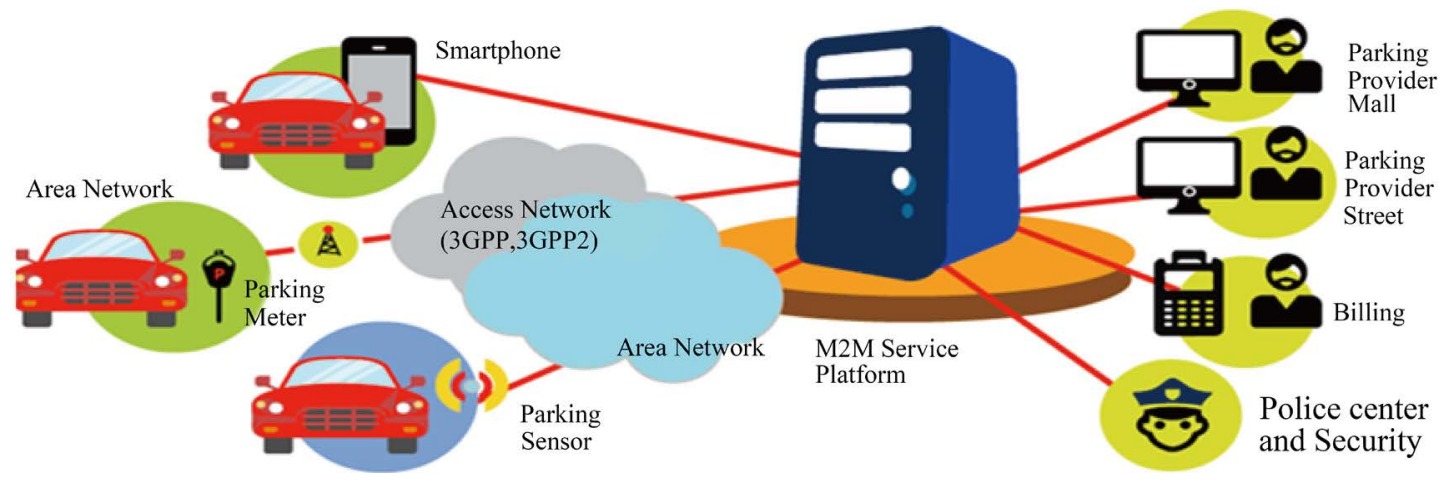

Figure 2. Using procedure of Park Easy, Android App.

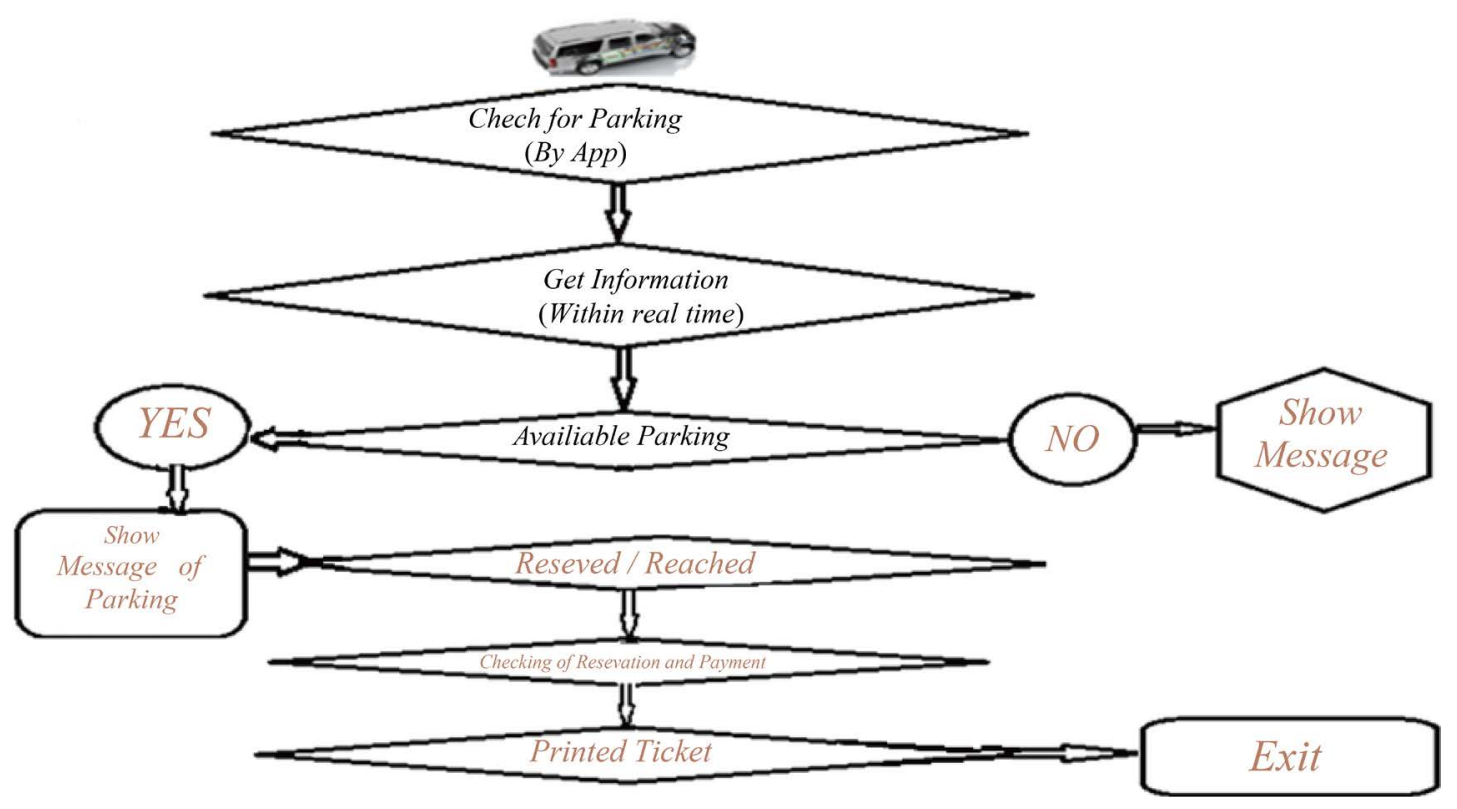

Figure 3. Flow chart of the process of the intelligent parking system.

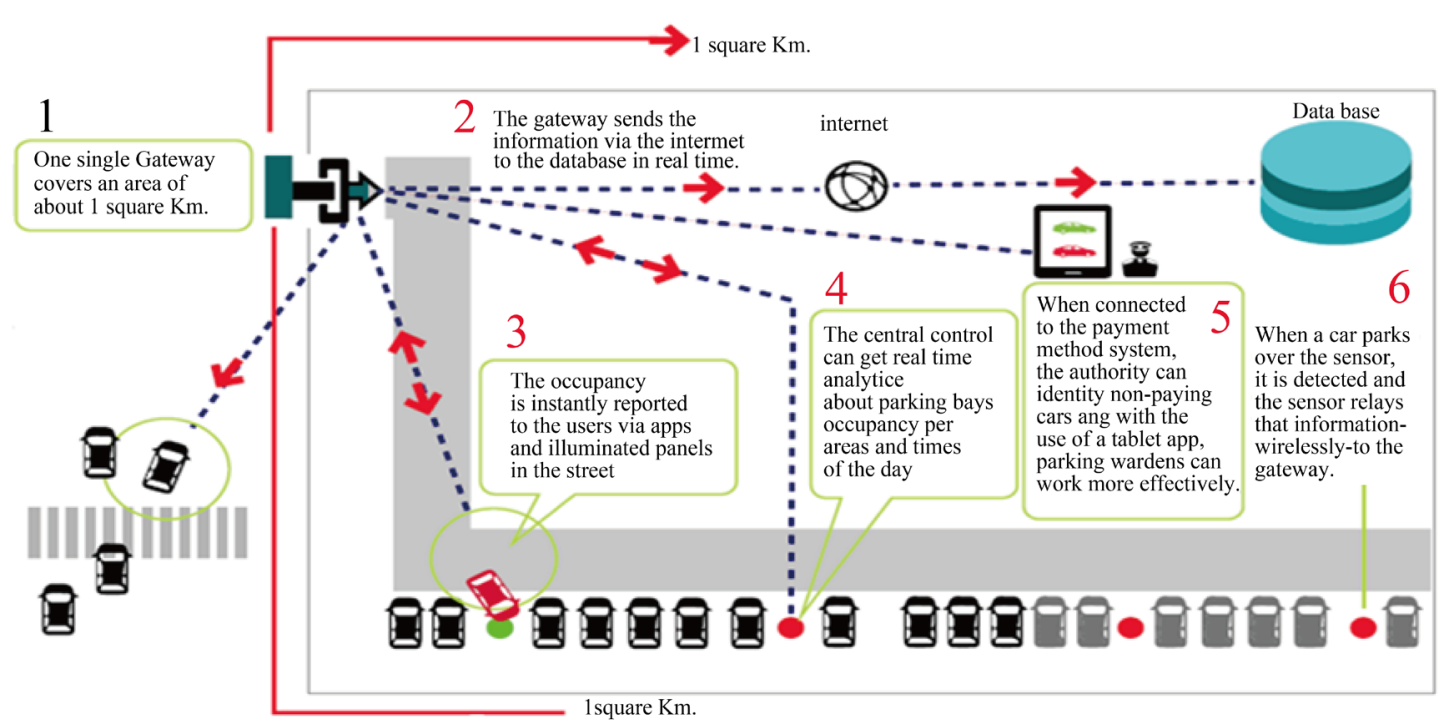

Figure 4. A typical sketch of working process of intelligent Parking System. 
- The Parking System includes three modules-Monitoring module, Control module and a displaying unit.

- The monitoring module includes ultrasonic sensors which identifies the free parking spaces and transmits the Information to control unit.

- Apart from detecting the car, the sensor also provides additional information like the stretch of time the car has been parked and also its health status.

- It also provides the possible shortage route to reach the parking lot.

- Along with these modules it will also have centralized system for supervisory and maintain a data base of parking space and will have a SMS gateway.

- The control units process the information and send the information to the supervisory system.

- Centralized system receives information of parking space from the controller. It then sends the information such as slot allotted, time parked, billing information and directional details to the user's mobile phone.

\subsection{Challenges for Implementing the Smart Parking System [1]}

This system is totally based on the internet with a wide range of network usage. It also depends on the automatic analyzing system involving the cameras, sensors and display unit. This system is also engaged with the online route providing system such as Google Maps, etc. so it must be using higher speed network. There are some more challenges are given as follows:

- The major challenge in implementing the Smart parking systems is of system integration due to wide variety of hardware and software platforms involved and hence possess a great threat or concern to the system scalability.

- The technology platform supporting those systems which comprises of a myriad of hardware sensors, dynamic messaging systems and traffic control devices, wireless, computer clients, servers, hardware drivers and application interfaces.

- Enabling all these devices from thousands of different vendors to communicate and tying them together into one platform is the greatest challenge in reducing the cost and complexity of smart parking. The varieties of infrastructure hardware and software systems that need to be integrated are enormous and add to it.

- Another major point comes from the electronic payment vendors. These payment processors provide permit based electronic payment, typically for a convenience fee. The key too many of these hosted solutions is scalability, the ability of the transaction processor to support over wide geographical, market and service areas, with minimal cost.

\section{Procedure}

The procedure flow of the entire system through M2M device from the app. Firstly, the User checks the availability of the parking spaces through "Park Easy" App, as shown in Figure 5. When the user enters the data of the desire spot for parking (for mall), it send the message to the service provider, who checks the availability of the parking space near about the user requirement spot. If the parking is available, it gives automatically feedback to the user.

If the user select the parking space, then the service provider give the automatic message of the parking charges to the user with the possible shortages route of the parking. And also give the message to the Parking provider after the payment of the parking space through online payment system, as shown in Figure 6.

Therefore, when the user reaches the parking lot, the street parking meter will detect the number plate of the car, and send the message to the parking provider just like the image capturing done by the Dr. Yair Wiseman [6]. Parking provider recommends the parking space to the navigator through M2M service device. This service procedure is shown in Figure 7.

Finally, when the user placed the car in the parking, with the selected time limit, the service provider gives the printed ticket to the user. The meter measure the time of the parking, after the selected time period, the On-Street parking meter intimate to the service provider and send a message to the user to remind about the park car. The leaving time of this car is also shown to the other users by searching in android app, "Park Easy". The final stage of this system is shown in Figure 8.

This shows the using procedure of the entire system with the help of smart phones. Park Easy App mainly helpful in reserve the parking spaces before the time of need.

The parking should be cleared vision, including the relaxation of time for the extension of parking need. This 


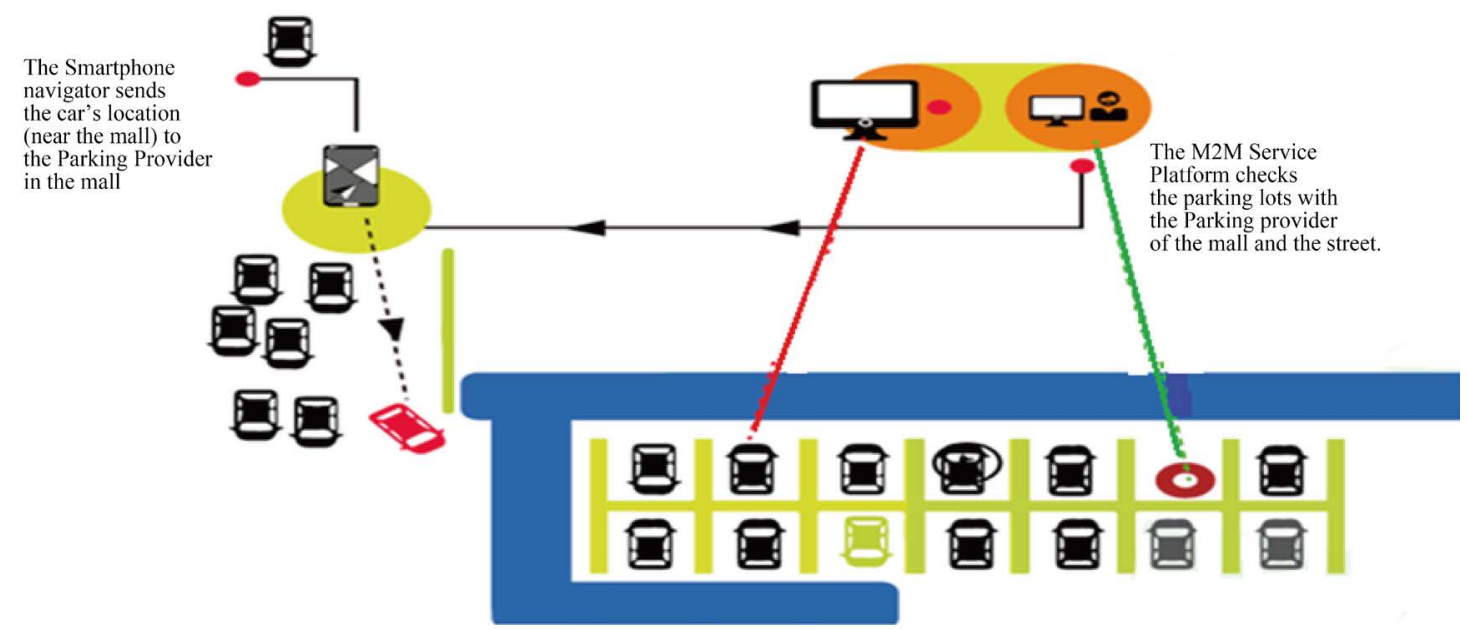

Figure 5. Sketch of the procedure of detecting of parking spaces.

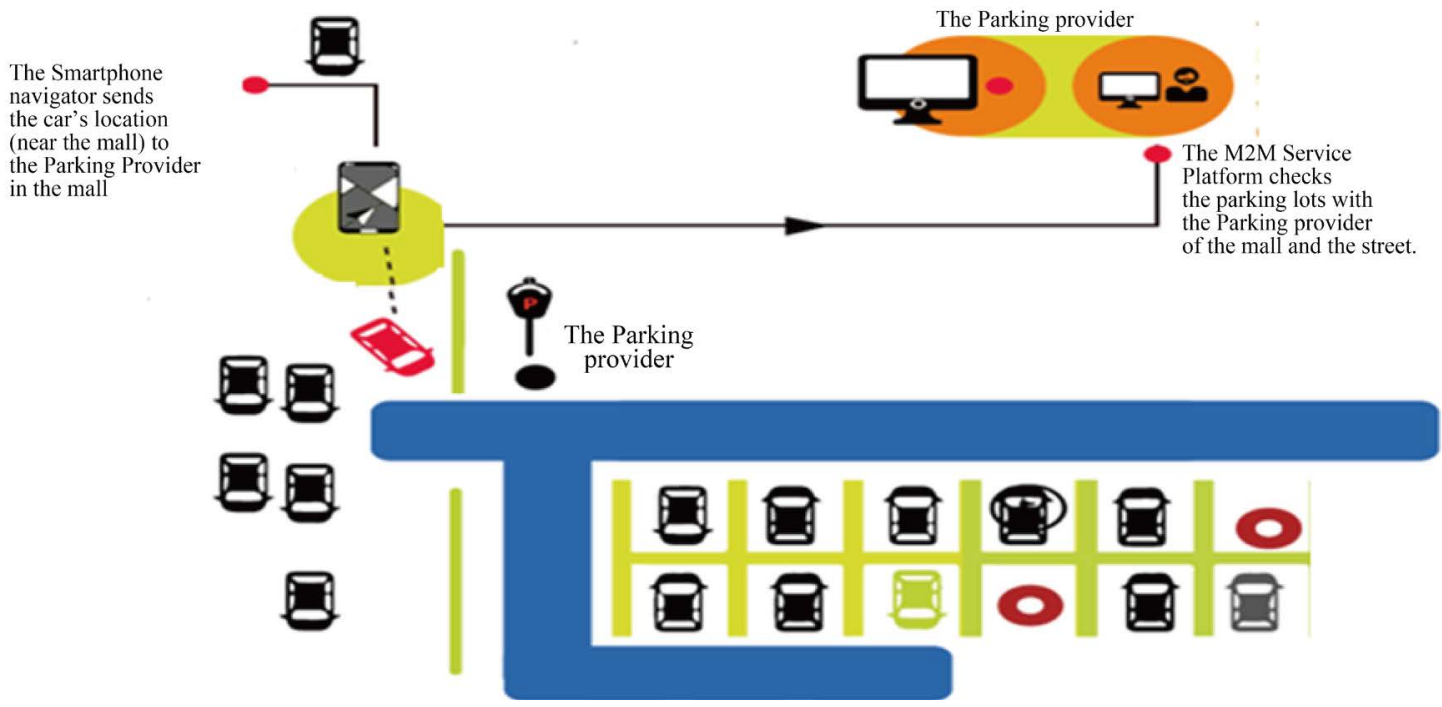

Figure 6. Sketch of the response of parking availability and reservation of parking.

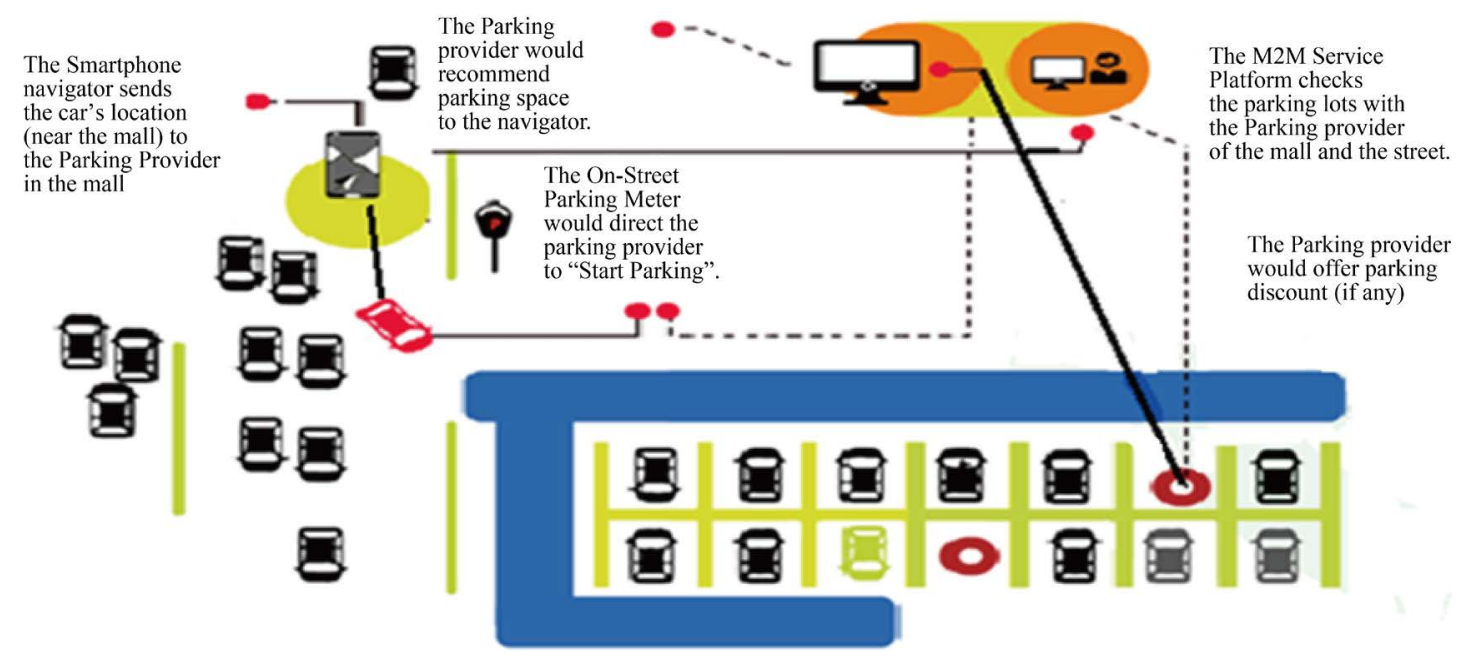

Figure 7. Sketch of service procedure. 


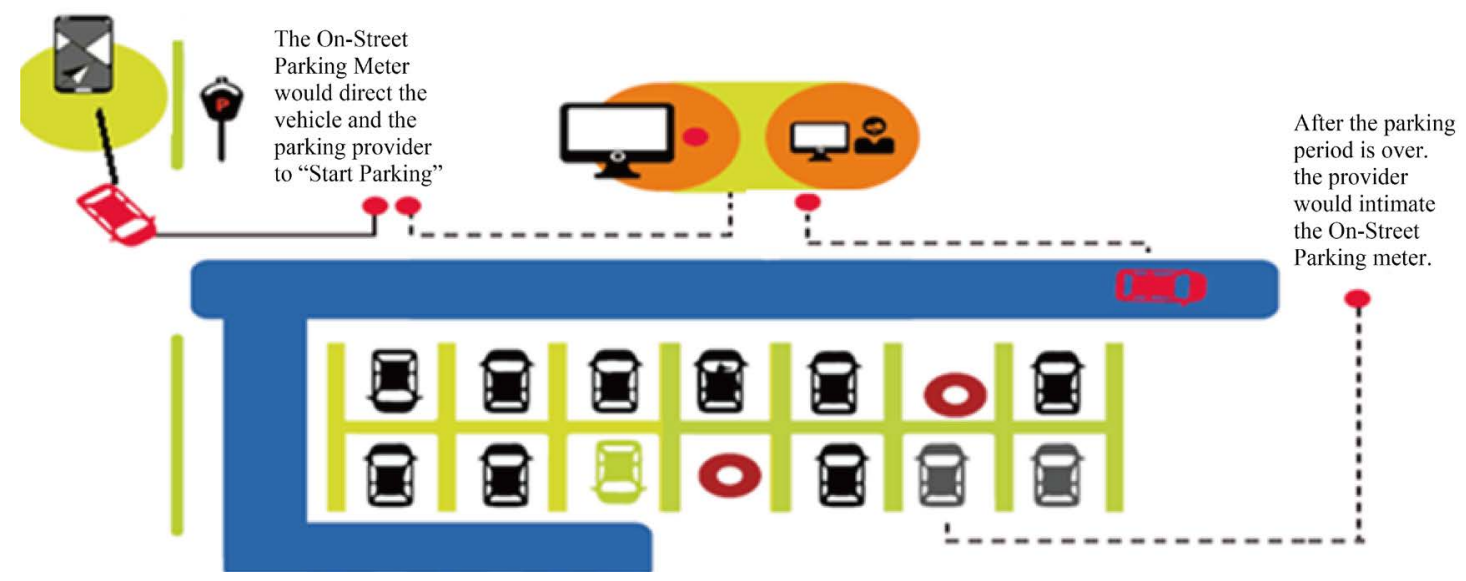

Figure 8. Final stage of the parking service.

relaxation should depend on the situation and site of the parking lots. This relaxation of time should be classified according to the saturation of the parking cars on sites or on locality, as blue zone, yellow zone and green zones. These zones show the activity of the moment and saturations of cars. According to the sequences:

- Blue Zone: Those zones which are most saturated like railway stations, airports, etc. In this zone, the extension of time limit is strictly prohibited and the relaxation time is only for two hours.

- Yellow Zone: Those zones which are saturated at peak hours. In this zone, the extension of time is limited in only peak hours such as commercial areas, markets, malls, etc. Rest of the day, the relaxation time will increases at certain limit with paying extra amount on extension.

- Green Zone: Those zones which are slightly saturated or the areas of college, institutes, parks etc. In this zone, the extension of time limit never prohibited and no extra amount is applied on increasing the time of parking.

\section{Conclusions}

Today, in the information age, the quest is for global economic efficiency in a world economy governed by environmental concerns, economic alliances, and trade agreements [7]. Due to the worldwide spread of motorization and urbanization raises new issues for city-developers. The industrialization of the world, increase in population, slow paced city development and mismanagement of the available parking space has resulted in parking related problems [8]. One of the key concerns of urban traffic is the growing size of the space occupied by parking cars which affect the traffic highly. Development of industrial automation has now reached the level where reliable and efficient solutions can be given into the hands of Smart parking designers. Modern parking has their possibilities, but they can only be exploited by using new architectural, mechanical and control solutions. Only an advanced, state-of-the-art control system can serve the increasing needs of customers.

Parking is difficult and costly system for implementation but Park Easy App gives the suitable way for utilizing the money and techniques and it also gives better revenue to the investors. Primarily smart parking technology is about enhancing the productivity levels and the service levels in operations. Some of the underlying benefits can be lowering operating costs, while building value for customer to drive occupancy, revenues and facility value. Proposed system will also decrease the traffic congestion as the number of vehicles parked on the street will decrease. These new systems will boost the parking business by the increase in the number of customers [9].

Finally, smart parking can actually transform the very makeup of our urban landscapes, making them more amenable to people rather than cars.

The field is constantly changing, and new techniques invent continuously, so software solutions will be expected to be tailored to type designs in the future. This requires continuous development and standardization of software modules.

\section{References}

[1] An Article of Smart Parking from Happiest Minds Technologies Pvt. Ltd. 
[2] Science Research Group (2014) Intelligent Parking Management System Based on Image Processing. World Journal of Engineering and Technology, 2, 55-67.

[3] Al-Kharusi, H. (2014) Intelligent Car Parking Management System. Master of Engineering Thesis.

[4] Al-Kharusi, H. (2014) Intelligent Car Parking Management System. Thesis, Master of Engineering, Electronic and Computer System Engineering, Massey University, Palmerston North, New Zealand.

[5] Siemens, A.G. (2001) Systematic Parking Solutions by Industrial Solutions and Services, Intelligent Traffic Systems. Ref. No. E10003-A800-W6-X-7600 Systematic Parking 6052 WS 1.0 Edition 003, 2001-12-01. http://www.siemens.de/traffic

[6] Wootton, J.R., Garcia-Ortiz, A. and Amin, S.M. (1995) Intelligent Transportation Systems: A Global Perspective. Mathematical and Computer Modelling, 22, 259-268.

[7] Faheem, S.A., Mahmud, G.M., Khan, M., Rahman and Zafar, H. (2013) A Survey of Intelligent Car Parking System. Elsevier, 11, 714-726.

[8] Zhang, X. and Wan, D. (2010) Economic Analysis of Regional Parking Guidance System Based on TIA. 2010 WASE International Conference on Information Engineering (ICIE), 14-15 August 2010, 401-404.

[9] Wiseman, Y. (2010) Take a Picture of Your Tire! Proc. IEEE Conference on Vehicular Electronics and Safety (IEEE ICVES-2010), Qingdao, 151-156. 